\title{
Water Electrified Sprays for Emission Control in Energy Production Processes
}

\author{
Di Natale F. ${ }^{1 *}$, Carotenuto C. ${ }^{2}$, Manna L. ${ }^{1}$, Esposito M. ${ }^{1}$, La Motta F. ${ }^{1}$, D’addio, L. ${ }^{3}$ and Lancia, \\ A. ${ }^{1}$ \\ ${ }^{1}$ Dipartimento di Ingegneria Chimica, dei Materiali e della Produzione Industriale, Università di \\ Napoli Federico II, P.le V. Tecchio 80 - 80125 Napoli (ITALY) \\ 2 Dipartimento di Ingegneria Industriale e dell'Informazione, Seconda Università di Napoli, Via \\ Roma 29 - 81031 Aversa, Caserta (ITALY) \\ ${ }^{3}$ Vessel Technical Services, Via F. Coppi 10 - 80010 Quarto, Napoli (ITALY)
}

Email: francesco.dinatale@unina.it

\begin{abstract}
Energy generation by fossil fuels produces significant amount of pollutants. Among the most toxic of them, there are $\mathrm{SO}_{2}$ and particulate matter. The first is a toxic gas that is subjected to severe regulations, the second is only partially regulated since the most toxic fractions of particles, i.e. the ultrafine particles, are nor easily measured neither properly captured by conventional technologies available at commercial level. Electrification of water sprays provide a reliable way to improve both the $\mathrm{SO}_{2}$ mass transfer rates and the particle capture efficiency, thanks to the multiple effects of electric charges imposed on the sprayed droplets. In this paper, we report experimental findings on the use of electrified sprays of water to reduce $\mathrm{SO}_{2}$ and particulate matter form a model flue gas. Tests were performed both laboratory and pilot scale. The experiments are compared with the performances of the same spray operated without electrification. In the pilot scale unit, particle removal efficiency is negligible and $\mathrm{SO}_{2}$ removal is up to $97 \%$ with the uncharged spray, The use of induction charging and exposure to corona pre-charging allow achieving $>93 \%$ reduction of particulate matter and to $>99 \% \mathrm{SO}_{2}$ reductions. Experiments at laboratory scale shed light on the mechanisms of particle and $\mathrm{SO}_{2}$ capture. In particular, the experimental results revealed that a stochastic scavenging model presented in our former works (data not shown) well described the particle capture and that for charged droplets, the absorption rate for $\mathrm{SO}_{2}$ improved by about $60 \%$ respect to uncharged droplets.
\end{abstract}

Keywords: Flue gas treatment, Ultrafine particle capture, $\mathrm{SO}_{2}$ capture, Wet Electrostatic scrubbing.

\section{INTRODUCTION}

This paper is part of an ongoing study aimed to investigate how electrically charged droplets interact with soot and with $\mathrm{SO}_{2}$, a dipolar molecule representing one of the main pollutants of industrial flue gases and Diesel engines exhausts. This phenomenon is at the bases of wet electrostatic scrubbers (WES). Our group proved that these new devices for gas cleaning can be suitably designed to capture ultrafine and nanometric carbonaceous particles from industrial [1] and engines [2-3] exhausts while simultaneously remove gaseous compounds like $\mathrm{SO}_{2}$ (e.g. [4]).

Carbonaceous particles are by-products of combustion, gasification or pyrolysis processes and result from undesired hydrocarbon pyrolysis reactions pathways (e.g. [5]). Carbonaceous particles include amorphous elemental carbon (EC), condensed PAH with high molecular weight forming the so-called organic carbon (OC), metal organic compounds, char, cenospheres, cokes etc. The EC, also denoted as (dry) soot, is composed by aggregates of nanometric spherules and is stable at temperature higher than $350^{\circ} \mathrm{C}$, while $\mathrm{OC}$ is in the form of condensed vapors and is usually classified as the fraction that volatilize above $350^{\circ} \mathrm{C}$. Elemental and organic carbon particles have usually sizes from 10 to $1000 \mathrm{~nm}$.

Indications on the global emission of soot derived from recent assessment on black carbon (BC) inventories. $\mathrm{BC}$ is the fraction of EC able to absorb light in the visible spectrum range and it is considered as the second most important climate-warming agent after $\mathrm{CO}_{2}$, having a radiative index of $1.1 \mathrm{~W} / \mathrm{m}^{2}$. In the comprehensive review of Bond et al. [6], the worldwide emission inventory of BC span within 4 and 29 MT/year, with an average value of $7 \mathrm{MT} /$ year. Significant contributions derive from biomass combustion, which are dominant in the South hemisphere, while $70 \%$ of the emissions in Europe, North America and Asia derives from industry and urban activities.

Ultrafine and nanometric particles are highly hazardous materials associated with enhanced adverse effects compared with larger ones (e.g. [7-13]). Among them, the International Agency for Research on Cancer (IARC) classified soot particles as a human mutagen and carcinogenic substance [14]. Indeed, particles surface area is a key toxicology 
parameter due to the amount of toxic gaseous species that adsorbs on particulate matter: at the same concentration, the finer the particle, the higher the surface area. Besides, finer particles penetrate deeper in the lungs and those smaller than $300 \mathrm{~nm}$ can cross cellular membranes. According to these observations, several toxicological and panel studies indicate that number concentration is the preferred metric for assessing particulate matter health effects. Paradoxically, with the exception of diesel cars, current air quality standards refer to mass concentration, so that actual emissions are below limits although in practice they preserve most of their toxicity. For example, a number concentration of $10^{12}$ particles $/ \mathrm{m}^{3}$, with an average particle diameter of $100 \mathrm{~nm}$ is extremely hazardous and corresponds to about $0.525 \mathrm{mg} / \mathrm{m}^{3}$. The same mass concentration can be achieved with only $6.4 \cdot 10^{7}$ particles $/ \mathrm{m}^{3}$ of $2.5 \mu \mathrm{m}$ particles.

Specific measures to reduce soot emissions should be adopted. Nowadays, in order to comply with regulations, diesel cars are usually equipped with Diesel particulate filters (DPF) and Diesel oxidation catalysts (DOC) that may reduce $90 \%$ of emitted particles. However, concerns about particulate and gaseous emissions during filters regenerations were reported [15]. For larger combustion units and engines, like ships, DPF and DOC are not adopted due to the high sulphur and ash content in the fuels. At industrial scale, dry and wet electrostatic precipitators (ESP) and filters (FF) are mainly used to control particle emissions. Jaworek et al. [16] reviewed conventional and innovative technologies for electrostatic precipitation of particles, showing that removal of submicron particles is a critical issue. Several innovations to conventional ESP have been proposed, as particle agglomerators, multi-stage ESPs, wet ESP and use of complex electrodes design, but their effectiveness must be still validated at the industrial scale. Particle conductivity and cohesiveness are the most critical process variables responsible for particle re-entrainment from the collection electrode. Charging efficiency of particles finer than $200 \mathrm{~nm}$ is very low and it makes the electrical drift velocity critical, requiring a reduction of the distance between discharge and plate electrodes, or higher residence time to make ESP effective.

Fabric filters are effective in removing particulate matters but are susceptible to gas humidity and tend to generate significant pressure drop to effectively remove particles finer than $200 \mathrm{~nm}$.

Wet electrostatic scrubbing (WES) can be an effective alternative process to remove submicron particles from gas stream in a market segment where ESP and FF are less effective [17-21]. Wet electrostatic scrubber is a spray tower equipped with an electrified spray unit for electrically charged water droplets generation and, optionally, a particle pre-charging unit. The electrostatic forces between droplets and particles lead to a more rapid and effective particle capture onto the droplets compared with conventional spray scrubbers [18, 22-27]. Besides, wet electrostatic scrubbers inherit all the structural and process advantages of conventional scrubbers as the low pressure drops and simple design and operation, as well as the ability to simultaneous removal of soluble gases. Jaworek et al. [22, 27] and Carotenuto et al. [18] described the fundamentals of wet electrostatic scrubbing.

The pertinent literature showed a large number of WES experiments on micrometric-size particles, indicating only a slight improvement of particle removal efficiency, compared to conventional scrubbers [18]. Conversely, tests performed on fine or ultrafine particles showed a steep increase of the removal efficiency. In previous studies [1, 19-21], our research group proved that, when submicron particles are scrubbed by uncharged droplets, negligible $(<1 \%)$ removal efficiencies were obtained. Otherwise, when the system operated as a wet electrostatic scrubber, the removal efficiency was at least one order of magnitude higher.

There are even less studies on $\mathrm{SO}_{2}$ absorption by charged droplets and the largest majority of them considered the interactions between a charged water spray and a gas stream containing $\mathrm{SO}_{2}$. Dou et al. [28] and Byun et al. [29] demonstrated that a spray of charged water exploited a higher absorption rate (up to one order of magnitude) than with a similar uncharged spray. In spite of this valuable result, it is complex to understand the underpinning physics of the process principally due to the complexities of charged sprays fluid-dynamics. In fact, Dou et al [28] suggested that a main reason for $\mathrm{SO}_{2}$ absorption rate increment was the reduction of droplet size and the better gas mixing that derived from the presence of electric charge on the sprayed liquid.

The electric charge on the spray droplets influences the absorption process in several ways. In particular, two main aspects should be considered: i) the effect of electric charges on chemical equilibrium of $\mathrm{SO}_{2}$ dissolution in water and ii) the effect of electric charge on the rate of $\mathrm{SO}_{2}$ mass transfer.

Several issues have arisen considering the effects of droplet charges on chemical speciation of dissolved ions. Theoretically, the presence of electric charges may influence the chemical speciation of dissolved $\mathrm{SO}_{2}$. However, preliminary indication on the maximum concentration of charge over a droplet suggested negligible effects on the water chemical speciation [4].

As regard the effects of electric charge on mass transfer rate, the pertinent literature provided three main indications related to: i) the reduction of droplets surface tension; ii) the occurrence of turbulence phenomena on the droplets surface and iii) the occurrence of electrostatic interactions between charged droplets and dipoles of gas molecules, as $\mathrm{SO}_{2}$. Matteson and Giardina [30] related the reduction of surface tension to an increase in the degree of polarization of interfacial water molecules. The authors linked this phenomenon to an increase of the concentration of ion $\mathrm{OH}^{-}$at the droplet interface and a parallel increase of $\mathrm{SO}_{2}$ absorption rate. Lopez-Herrera et al. [31] showed that electric charges caused droplet oscillation that may give rise to additional vortices and increased the interfacial area and the mass transfer rate [32]. Finally, Wang and Luo [33] presented a model for the capture of $\mathrm{SO}_{2}$ on charged droplets based on the assumption that the additional mass transfer depend on the electrostatic interactions between the droplet charges and the $\mathrm{SO}_{2}$ dipole. However, its derivation is valid in the pure void, when the thermic motion of the gas is absent.

In this paper, we report experimental findings on the removal of $\mathrm{SO}_{2}$ and soot from a model combustion flue gas in two different WES prototypes. Tests on effectiveness of particles and $\mathrm{SO}_{2}$ removal in a WES unit were carried out in a pilot scale unit where the polluted gas firstly passed through a negative corona charging and then entered a scrubber where a single nozzle was operated either charged or uncharged. Tests at lab scale were performed to estimate the $\mathrm{SO}_{2}$ absorption rate in charged and uncharged droplets of controlled size, shape and velocity, following the indication reported in Di Natale et al. [4]. Experiments on particle removal in the same unit are reported in D'Addio et al. $[19,20]$ and Di Natale et al. [21]. 


\section{MATERIALS AND METHODS}

\subsection{Lab scale experimental set up for $\mathrm{SO}_{2}$ absorption}

The experimental approach consider the use of a lab-scale WES chamber equipped with one electrospray nozzle, operating in dripping mode. A regular train of droplets was produced to scrub a particles-laden gas contained in the chamber. The system was operated batchwise and the $\mathrm{SO}_{2}$ concentration was measured over time. The experimental plant layout is shown in Figure 1.

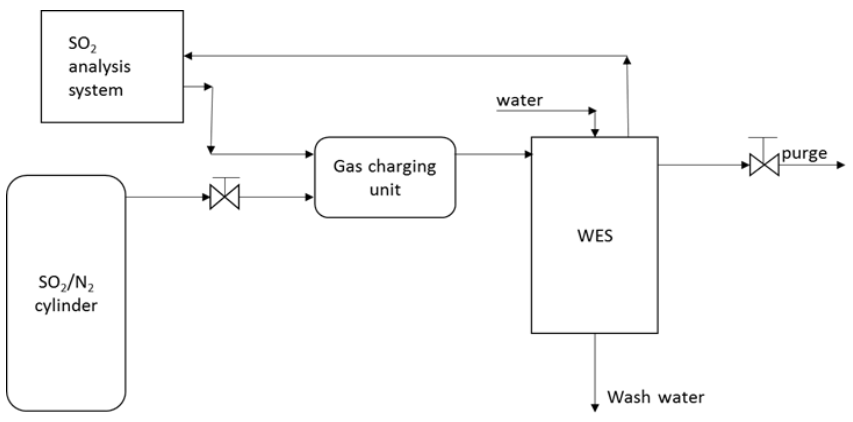

Figure 1. Layout of the laboratory scale system

The main components of the plant are the water electrostatic scrubber (WES), which included the charged droplet generation system and the gas-charging unit (GCU), described in D'Addio et al. [19-20]. The gas analysis instrumentation, which consisted in an ACD MAG3000C equipped with a chiller and a dryer to avoid interferences in the $\mathrm{SO}_{2}$ determination.

The cylindrical WES chamber (height: $200 \mathrm{~mm}$, ID: 100 $\mathrm{mm}$ ) was made of Plexiglas ${ }^{\circledR}$. The dimensions of the chamber were selected to facilitate operation and maintenance procedures and to allow easy placement of measurement probes. The lateral surface of the WES was covered with a wire mesh and connected to ground potential to shield the chamber from external electric noises. The WES chamber had a removable lid on the top that contained the electrospray nozzle assembly, which was capable of producing a train of droplets with known size and charge values. The gas was sampled through a hole on the lateral surface. Once sampled, the gas was recirculated in the chamber. This recirculation avoided the pressure decrease in the WES chamber, which might cause the unwanted entrance of external air, and it assured well mixing conditions.

The charged droplets generation system consisted in a stainless steel capillary needle $(\mathrm{OD}=0.8 \mathrm{~mm}, \mathrm{ID}=0.25 \mathrm{~mm})$ coaxial to a grounded steel ring encased in a PTFE box and connected to a high voltage power supply (Bertan, mod. 23020R). The needle tip was located $1 \mathrm{~mm}$ below the lower surface of the ring [20]. The liquid was fed into the needle using a syringe pump. The liquid flow rate was controlled with a rotameter (Rota Yokogawa, mod. RAGK41) operating between $0.15-2.2 \mathrm{ml} / \mathrm{min}$. Water electric conductivity was measured with the Elmertron conductivity meter (mod. CPC401). The humidity and the temperature of the unit were monitored according to the experimental procedure of $\mathrm{Di}$ Natale et al. [21].

The gas was a calibrated mixture with $1000 \pm 50 \mathrm{ppm}$ of $\mathrm{SO}_{2}$ in $\mathrm{N}_{2}$. The sprayed liquid was distilled water with $\mathrm{HCl}$ having a $\mathrm{pH}$ of $2.5 \pm 0.05$. This acid $\mathrm{pH}$ value was chosen to operate with a pure physical absorption system whose solubility depended only on $\mathrm{SO}_{2}$ liquid-vapor equilibrium.

In order to provide a correct interpretation of experimental results, a detailed analysis of sprayed droplet size, frequency and charge was required. This was carried out according to D'Addio et al. [20].

The experimental protocol for $\mathrm{SO}_{2}$ absorption consisted in: i) filling the WES chamber with the $\mathrm{SO}_{2}$-laden gas, ii) switching on the water electrospray and then iii) measuring $\mathrm{SO}_{2}$ concentration over time. The tests were carried out batchwise for 10 minutes. To compare experiments performed in different days and with different gas cylinders, the ratio $\mathrm{C} / \mathrm{C}_{0}$ between the instantaneous and the initial value of $\mathrm{SO}_{2}$ concentration were plotted against the test time, t. In the experimental timeframe, the concentration of $\mathrm{SO}_{2}$ in the WES chamber followed an almost linear time-course, and each test was resumed with a characteristic slope named $\beta$. Each test was repeated in triplicate and the values of $\beta$ were averaged. The maximum standard deviation of $\beta$ data was $3 \%$, testifying the accuracy of the experimental tests. The tests run consists in five steps:

A. blank test (without sprayed water);

B. Test with uncharged water;

C. 2 run tests with water charged at $2 \mathrm{kV}$;

D. Test with uncharged water;

E. Blank test.

While specific values of the slopes $\beta$ may have small variations, the tests $\mathrm{C}, \mathrm{B}$ and $\mathrm{D}$ were always consistent and the relative differences between the two couple of runs were preserved. In this set of experiments, the GCU unit was switched off.

\subsection{Pilot scale prototype}

The pilot scale set up is shown in Figure 2.

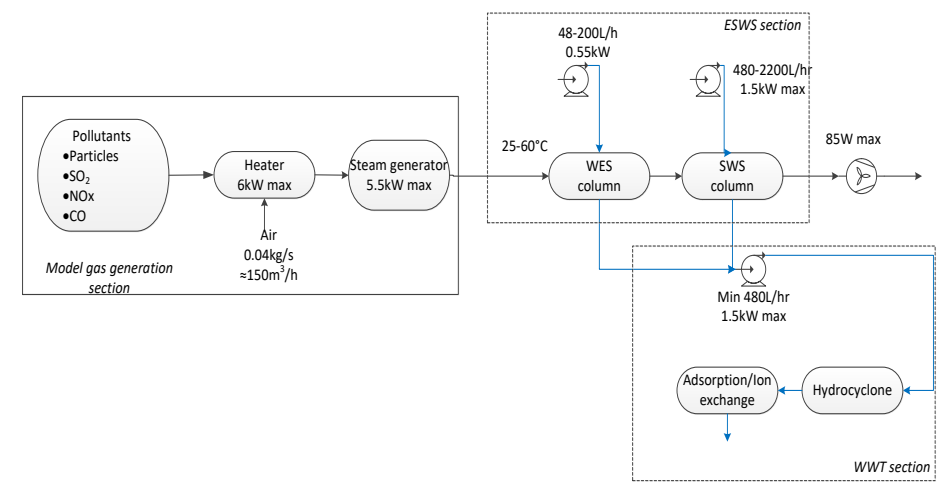

Figure 2. General laoyut of the pilot-scale wet electrostatic scrubber. (black thin lines identify gas streamlines, blu bold lines identify water streamlines) 
The unit was developed within the activity of the $7^{\text {th }}$ European Framework Programme project DEECON and consisted in:

A model gas generation system (including cylinders, heaters and humidification units);

A quencher for gas conditioning;

Three water tanks: one collects $2 \mathrm{~m}^{3}$ of tap water to be fed to the entire plant; one collects up to $2 \mathrm{~m}^{3}$ of water coming out from the plant, one small buffer tank collects the water that comes out from the bottom of WES, SWS and quencher columns and that has to be treated in the WWT unit;

A wet electrostatic seawater scrubber (WES) sized to remove submicron particulate matter and acid gases. This unit include a particle-charging unit (PCU) and an electrified spray (ES).

A seawater scrubber (SWS) sized to remove $\mathrm{SO}_{2}$ and other acid gases at state of art levels by integration with the WES system.

Analytical instrumentations and gas conditioning devices for the analysis of particulate matter and gas;

- Measurement instrumentations for process control (manual);

- $\quad$ A PLC and an electric cabinet;

- $\quad$ Electric high voltage generators;

- $\quad$ Electric fan for adduction of gas to the ESWS unit;

- Water pumps.

Details on the size of the WES and SWS (twin) columns and on the characteristics of droplet particle charging were reported in Di Natale et al. [1]

All tests were carried out with a model exhaust produced by combustion of gasoline mixed with a gas mixture containing adjustable concentrations of $\mathrm{SO}_{2}, \mathrm{NO}$ and $\mathrm{CO}$ to simulate typical levels of these pollutants in real diesel exhausts gases. A gas stream of $100-150 \mathrm{Nm}^{3} / \mathrm{h}$ containing particles from 10 to $1000 \mathrm{~nm}$ with a total concentration of $3 \cdot 10^{12} \# / \mathrm{m}^{3}$ was used for all the tests. Particle size distribution appeared bimodal with one peak at about $30 \mathrm{~nm}$ and another one at about $150 \mathrm{~nm}$. Besides, $99 \%$ of the particles had size lower than $400 \mathrm{~nm}$.

Mostly they were in the field of ultrafine particles. The exhaust gases were diluted with ambient air, heated at desired temperature and humidified to saturation.

Common tap water was used for the tests. This was characterised by a $\mathrm{pH}$ of about 7.8 and an alkalinity of about $2.57 \mathrm{mmol} / \mathrm{L}$, similar to that of seawater.

These tests were carried out by changing the gas and liquid mass ratio, the droplets and particles charges, and using both the WES and the SWS columns. The WES column was operated with co-current flows, with both the gas and the water entering on its upper section and moving downward. The electrified nozzle was a Lechler 460-484, which provided a $\mathrm{D}_{32}$ of $288.5 \mu \mathrm{m}$. Di Natale et al. [1] discussed details of the ES and the PCU units.

The SWS had the same design of the WES column, but the gas was fed upward from the bottom section of the column and the liquid was fed by four hydraulic nozzles (PNR Model BRB 2117 B1) operated at pressure of 3 bar (mean Sauter diameter $\mathrm{D}_{32}=266.40 \mu \mathrm{m}$; mean jet velocity $=20.6 \mathrm{~m} / \mathrm{s}$ ).

\section{RESULTS AND DISCUSSION}

Experimental plot on the absorption of $\mathrm{SO}_{2}$ by charged and uncharged droplets investigated in the lab scale set up, as well as for the blank tests, are shown in Figure 3.

Experiments revealed that the setup itself was responsible for about $30 \%$ of the removed $\mathrm{SO}_{2}$ (capturing about $50 \mathrm{ppm}$ of $\mathrm{SO}_{2}$ after $200 \mathrm{~s}$ ). The net contribution of sprayed droplets is well distinguishable from the blank test and the $\mathrm{SO}_{2}$ absorbed by the water after $200 \mathrm{~s}$ was $13 \%$ higher for charged droplets than for uncharged ones. The curve slopes $(\beta)$ for 0 and $2 \mathrm{kV}$ were $2.07 \cdot 10^{-5} \mathrm{~mol} / \mathrm{m}^{3} \mathrm{~s}$ and $3.01 \cdot 10^{-5} \mathrm{~mol} / \mathrm{m}^{3} \mathrm{~s}$, respectively. For the blank tests $\beta$ was $7.56 \cdot 10^{-6} \mathrm{~mol} / \mathrm{m}^{3} \mathrm{~s}$ regardless the needle charging potential.

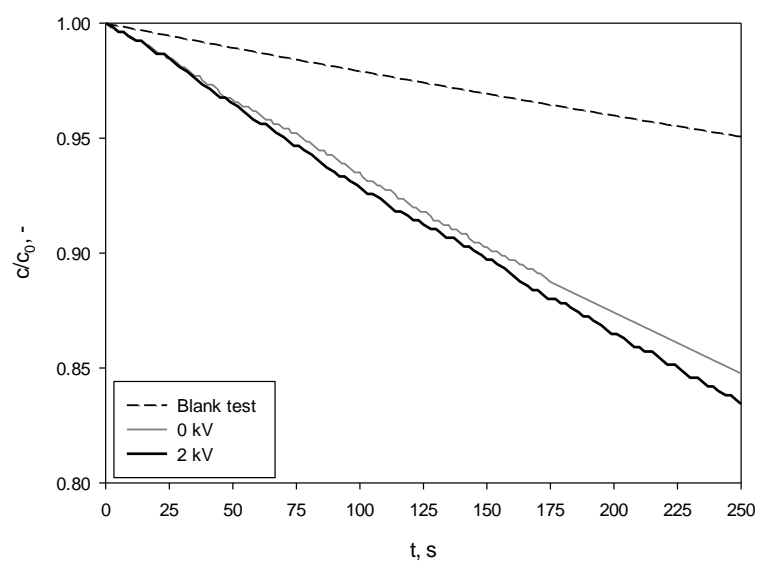

Figure 3. Dimensionless $\mathrm{SO}_{2}$ concentration time course in the lab scale WES chamber during blank test (no water) and with uncharged and charged water. $\mathrm{C}_{0}=1000 \mathrm{ppm}$; Distilled water with $\mathrm{HCl}$ at $\mathrm{pH}=2.5 ; \mathrm{T}=20^{\circ} \mathrm{C}$.

Figures 4 and 5 show the pilot scale results in terms of $\mathrm{SO}_{2}$ abatement and particle capture, respectively.

Figure 4 shows the total $\mathrm{SO}_{2}$ removal efficency achieved at the exit of the SWS unit coupled with the WES when this was operated as a conventional uncharged scrubber and when it was operated with a charging potential of $15 \mathrm{kV}$ for both PCU and ES units. Experiments on $\mathrm{SO}_{2}$ absorption were performed at three different gas temperatures with a gas flow rate of $120 \mathrm{Nm}^{3} / \mathrm{h}$ and a liquid flow rate of $195 \mathrm{~L} / \mathrm{min}$.

The experimental findings clearly indicated that, whatever the gas temperature was, the $\mathrm{SO}_{2}$ absorption with the charged WES unit was up to two percent point higher than with the WES operated as uncharged. With such high levels of removal efficiencies, a similar improvement is not negligible. Indeed, it indicated that residual $\mathrm{SO}_{2}$ emissions reduced by a factor between 2 and 3 by using a charged spray.

We performed tests on particle scrubbing with electrified seawater at three gas flow rates and at constant liquid flow rate of $195 \mathrm{~L} / \mathrm{h}$. Both particles and droplets charging units were set at $\mathrm{V}=15 \mathrm{kV}$. It is worth noticing that the higher gas flow rate leaded to a higher particle concentration and to a certain increase of the average particle size. Figure 5 shows a plot of the total particle mass removal efficiency as a function of gas flow rate. During these tests, the SWS unit was switched-off but we eventually verified that, if operated, it did not play any role in capturing particles as fine as the investigated ones.

These experiments showed that higher gas flow rates led to a lower particle capture efficiency as a consequence of the lower $\mathrm{L} / \mathrm{G}$ ratio and the lower contact time in the wet 
electrostatic scrubbers. However, no particle removal was measured once the WES column was operated as a conventional uncharged unit. These results were consistent with particle scavenging model, as reported in D'Addio et al. [19-20] and Di Natale et al. [21].

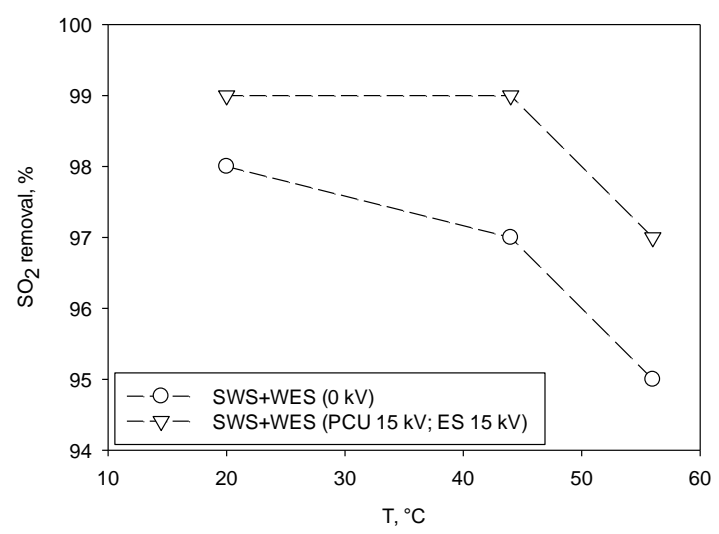

Figure 4. $\mathrm{SO}_{2}$ absorption efficiency as a function of gas temperature at the pilot-scale scrubber exit. WES: $\mathrm{L}=195 \mathrm{~L} / \mathrm{h}, \mathrm{SWS}: \mathrm{L}=1500 \mathrm{~L} / \mathrm{h} . \mathrm{G}=120 \mathrm{Nm}^{3} / \mathrm{h}$

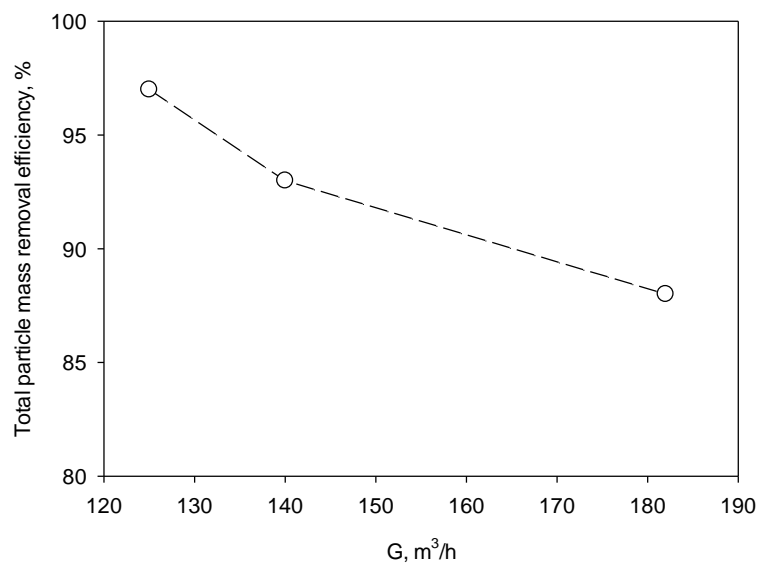

Figure 5. Mass particle removal efficeincy as a function of gas flow rate $(\mathrm{PCU}$ potential $=15 \mathrm{kV}$; ES potential $=15 \mathrm{kV})$ in the pilot scale scrubber at $\mathrm{L}=195 \mathrm{~L} / \mathrm{h}$

\section{CONCLUSIONS}

Experimental findings on the capture of $\mathrm{SO}_{2}$ and soot particle capture by means of charged droplets are reported. Experiments were carried out with both a laboratory and a pilot scale experimental set up.

At a lab scale, we performed experiments to achieve more details about the absorption rate of $\mathrm{SO}_{2}$ in charged droplets in absence of the physical hindrances posed by the use of a fullscale spray. This experimental setup clearly indicated that charged droplets actually had higher absorption rate, which depended on a modification of both droplets shape and interfacial properties.

At pilot scale, the experiments proved that the use of a charged water spray and a corona charging allowed improving the quality of emitted gas by reducing the particles concentration up to about $97 \%$ in weight - whereas uncharged spray provided negligible removal efficiency - and reducing the $\mathrm{SO}_{2}$ emission by more than $50 \%$ compared with uncharged sprays.

\section{ACKNOWLEDGMENT}

This study was partly financed by the Project: "RAIN Rimozione avanzata di Inquinanti da motori diesel navali "POR Campania FESR 2007-2013 Interventi a favore delle PMI e degli organismi di ricerca- Sportello dell'innovazione and by the Project "DEECON Innovative after Treatment System for Marine Diesel Engine Emission Control" Seventh European Framework Programme. We also thank Eng Procolo Volpe (VTS-Vessel Technical Service, Italy) for his support in setting up of the experimental system.

\section{REFERENCES}

[1] Di Natale, F., Carotenuto, C., D'Addio, L., Jaworek, A., Krupa, A., Szudyga, M. and Lancia, A., "Capture of fine and ultrafine particles in a wet electrostatic scrubber," Journal of Environmental Chemical Engineering, vol. 3, pp. 349-356, 2015.

[2] Di Natale, F., Carotenuto, C., D'Addio, L., Lancia, A., Antes, T., Szudyga, M., Jaworek, A., Gregory, D., Jackson, M., Volpe, P., Beleca, R., Manivannan, N., Abbod, M. and Balachandran, W., "New technologies for marine diesel engine emission control," Chemical Engineering Transactions, pp. 361-366, 2013.

[3] Di Natale, F. and Carotenuto, C., "Particulate matter in marine diesel engines exhausts: Emissions and control strategies," Transportation Research Part D: Transport and Environment, vol. 40, pp. 166-191, 2015.

[4] F. Di Natale, C. Carotenuto and A. Lancia, "Enhanced $\mathrm{SO}_{2}$ removal by using charged water droplets," Chemical Engineering Transactions, vol. 52, 2016, in press.

[5] S. A. Cormier, S. Lomnicki, W. Backes and B. Dellinger, "Origin and health impacts of emissions of toxic by-products and fine particles from combustion and thermal treatment of hazardous wastes and materials," Environmental Health Perspectives, vol. 114, pp. 810-817, 2006.

[6] T. C. Bond, S. J. Doherty, D. W. Fahey, P. M. Forster, T. Berntsen, B. J. DeAngelo, M. G. Flanner, S. Ghan, B. Kärcher, D. Koch, S. Kinne, Y. Kondo, P.K. Quinn, M. C. Sarofim, M. G. Schultz, M. Schulz, C. Venkataraman, H. Zhang, S. Zhang, N. Bellouin, S. K. Guttikunda, P. K. Hopke, M. Z. Jacobson, J. W. Kaiser, Z. Klimont, U. Lohmann, J. P. Schwarz, D. Shindell, T. Storelvmo, S. G. Warren and C. S. Zender, "Bounding the role of black carbon in the climate system: A scientific assessment," Journal of Geophysical Research: Atmospheres, vol. 118, pp. 5380-5552, 2013.

[7] T. D. Tetley, Health effects of nanomaterials, Biochemical Society Transactions, vol. 35, pp. 527531, 2007. 
[8] C. Wang, S.K. Friedlander and L. Mädler, "Nanoparticle aerosol science and technology: an

[9] P. Kumar, A. Robins, S. Vardoulakis and R. Britter, "A review of the characteristics of nanoparticles in the urban atmosphere and the prospects for developing regulatory controls," Atmospheric Environment, vol. 44, pp. 5035-5052, 2010.

[10] P. Kumar, M. Ketzel, S. Vardoulakis, L. Pirjola and R. Britter, "Dynamics and dispersion modelling of nanoparticles from road traffic in the urban atmospheric environment-A review," Journal of Aerosol Science, vol. 42, pp. 580-603, 2011.

[11] J.K.W. Chan, M. V. Fanucchi, D. S. Anderson, A. D. Abid, C. D. Wallis, D. A. Dickinson, B. M. Kumfer, I. M. Kennedy, A. S. Wexler and L. S. Van Winkle, "Susceptibility to inhaled flame-generated ultrafine soot in neonatal and adult rat lungs," Toxicological Sciences, vol. 124, pp. 472-486, 2011.

[12] L. Levy, I. S. Chaudhuri, N. Krueger, R. J. McCunney, "Does carbon black disaggregate in lung fluid? A critical assessment," Chemical Research in Toxicology, vol. 25, pp. 2001-2006, 2012.

[13] Z. H. Zhang and R. Balasubramanian, "Physicochemical and toxicological characteristics of particulate matter emitted from a non-road diesel engine: Comparative evaluation of biodiesel-diesel and butanol-diesel blends," Journal of Hazardous Materials, vol. 264, pp. 395-402, 2014.

[14] International Agency for Research on Cancer, IARC: Diesel engine exhaust carcinogenic in, 2012, pp. 4.

[15] A. Mamakos and G. Martini, "Particle Number Emissions during Regeneration of DPF-equipped Light Duty Diesel Vehicles," JRC Scientific and Technical Reports, JRC64870, 2011.

[16] A. Jaworek, A. Krupa and T. Czech, "Modern electrostatic devices and methods for exhaust gas cleaning: A brief review," Journal of Electrostatics, vol. 65, pp. 133-155, 2007.

[17] C. Carotenuto, L. D'Addio, M. Capocelli and F. Di Natale, "Diesel particle abatement by wet electrostatic scrubbing," in Proocedings of the 19th International Congress of Chemical and Process Engineering, CHISA 2010 and 7th European Congress of Chemical Engineering, ECCE-7, Prague, pp. 1981-1982, 2010.

[18] C. Carotenuto, F. Di Natale and A. Lancia, Wet electrostatic scrubbers for the abatement of submicronic particulate," Chemical Engineering Journal, vol. 165, pp. 35-45, 2010.

[19] L. D'Addio, F. Di Natale, C. Carotenuto, W. Balachandran and A. Lancia, "A lab-scale system to study submicron particles removal in wet electrostatic scrubbers," Chemical Engineering Science, vol. 97, pp. 176-185, 2013.

[20] L. D'Addio, C. Carotenuto, W. Balachandran, A. Lancia and F. Di Natale, "Experimental analysis on the capture of submicron particles (PM0.5) by wet electrostatic scrubbing," Chemical Engineering Science, vol. 106, pp. 222-230, 2014. overview," China Particuology, vol. 3, p. 12, 2005.

[21] Di Natale, F., Carotenuto, C., D'Addio, L. and Lancia, A., "Effect of gas temperature on the capture of charged particles by oppositely charged water droplets," Aerosol Science and Technology, vol. 50, pp. 110-117, 2016.

[22] A. Jaworek, W. Balachandran, A. Krupa, J. Kulon and M. Lackowski, "Wet electroscrubbers for state of the art gas cleaning," Environmental Science and Technology, vol. 40, pp. 6197-6207, 2006.

[23] A. Bologa, H.-R. Paur and T. Wäscher, "Electrostatic charging of aerosol as a mechanism of gas cleaning from submicron particles," Filtration and; Separation, vol. 38, pp. 26-30, 2001.

[24] W. Balachandran, A. Jaworek, A. Krupa, J. Kulon and M. Lackowski, "Efficiency of smoke removal by charged water droplets," Journal of Electrostatics, vol. 58, pp. 209-220, 2003

[25] A. Jaworek, W. Balachandran, M. Lackowski, J. Kulon and A. Krupa, "Multi-nozzle electrospray system for gas cleaning processes," Journal of Electrostatics, vol. 64, pp. 194-202, 2006.

[26] T. Ha, O. Nishida, H. Fujita and H. Wataru, "Enhancement of diesel particulate matter collection in an electrostatic water-spraying scrubber," Journal of Marine Science and Technology, 2010.

[27] A. Jaworek, A. Krupa, A. T. Sobczyk, A. Marchewicz, M. Szudyga, T. Antes, W. Balachandran, F. Di Natale and C. Carotenuto, "Submicron particles removal by charged sprays. Fundamentals," Journal of Electrostatics, vol. 71, pp. 345-350, 2013.

[28] Dou, B., Byun, Y. C. and Hwang, J., "Flue gas desulfurization with an electrostatic spraying absorber," Energy and Fuels, vol. 22, pp. 1041-1045, 2008.

[29] Byun, Y. C., Jung, J. Y. and Hwang, J., “Application of electrostatic spraying to reduce $\mathrm{SO}_{2}$ emission in a laboratory-scale spray drying absorber," Journal of Aerosol Science, vol. 29, pp. S479-S480, 1998.

[30] Matteson, M. J. and Giardina, P. J., "Mass transfer of sulfur dioxide to growing droplets: Role of surface electrical properties," Environmental Science and Technology, vol. 8, pp. 50-55, 1974.

[31] López-Herrera, J. M., Popinet, S. and Herrada, M. A., "A charge-conservative approach for simulating electrohydrodynamic two-phase flows using volumeof-fluid," J. Comp. Physics, vol. 230, pp. 1939-1955, 2011.

[32] Clift, R., Grace, J. R., Weber, M. E., Bubbles, Drops and Particles, Academic Press, New York, 1978.

[33] Wang, Z. amd Luo, T., "Model and simulation on SO2 removal with electrostatic spray," Bioinformatics and Biomedical Engineering, (iCBBE) 20115 th International Conference on, pp. 1-4, 2011. 